EGU2020-1429

https://doi.org/10.5194/egusphere-egu2020-1429

EGU General Assembly 2020

(c) Author(s) 2020. This work is distributed under

the Creative Commons Attribution 4.0 License.

\title{
Positive Matrix Factorization and GIS approach to perform data mining on groundwater and surface water quality dataset.
}

\author{
Chiara Zanotti ${ }^{1}$, Marco Rotiroti ${ }^{1}$, Letizia Fumagalli ${ }^{1}$, Gennaro Stefania ${ }^{1}$, Francesco Canonaco ${ }^{2}$, \\ Giulia Stefenelli ${ }^{2}$, Andre Prévôt ${ }^{2}$, Barbara Leoni ${ }^{1}$, and Tullia Bonomi ${ }^{1}$ \\ ${ }^{1}$ University of Milano - Bicocca, Milano, Italy (c.zanotti@campus.unimib.it) \\ ${ }^{2}$ Laboratory of Atmospheric Chemistry, Paul Scherrer Institute, 5232 Villigen-PSI, Switzerland
}

Positive Matrix Factorization (PMF) is a multivariate analysis aimed at source identification and apportionment, specifically designed to cope with environmental data and manage their uncertainty and distributions. The aim of this work is to test the effectiveness of PMF as a tool to perform data mining and define hydrochemical features of groundwater and surface water and to understand their relationship. Here PMF is applied to a dataset concerning groundwater, springs, rivers and a lake. Factor contributions to the samples are spatially analysed trough GIS approach and their interpretation is supported by considering the land use and hydrogeological features.

The study area is a part of the Oglio River basin ( $\mathrm{N}$ Italy) and consists in a $2000 \mathrm{~km}^{2}$ area around the Oglio River part that outflows from Lake Iseo until the confluence with Mella River. The available dataset is the result of four field surveys conducted in February 2016, June 2016, September 2016 and March 2017, for a total amount of 270 samples collected on 68 monitoring points.

The first factor represents water with a high content of oxygen, with $\mathrm{SO} 4$ and a small content of major ions. In this factor neither nitrate nor trace elements are represented. The profile of this factor overlaps with the characteristics of lake Iseo and surface water bodies directly connected with it. Its spatial variability highlights a contribution of this factor, also in several wells even if they are not close to the river itself. This was related to the channels net collecting water from the Oglio River and spreading it to the nearby fields.

The second factor explains the whole chemical variability of $\mathrm{As}, \mathrm{Fe}, \mathrm{P}$-tot and $\mathrm{NH}_{4}$. Furthermore, it has a significant contribution of $\mathrm{Mn}$ and it can be associated to the advanced stages of reducing conditions due to degradation of natural organic matter.

The third factor is characterized mainly by $\mathrm{Mn}$ and $\mathrm{SO}_{4}$, with a contribution of the major ions. Based on the profile and on the spatial distribution, it is possible to associate this factor to the early stages of the reducing process.

The fourth factor represents only major ions. Major ion concentration in groundwater is mainly determined by water - rock interactions, which increase the concentrations especially with 
increasing residence times. This factor shows an increasing trend from north to south, which is the flow direction, confirming its relationship with residence time.

The fifth factor represents the total variability of the variable $\mathrm{NO}_{3}$ with contributions also in terms of $\mathrm{Cl}, \mathrm{SO}_{4}, \mathrm{Ca}$ and $\mathrm{Mg}$. Higher $\mathrm{NO}_{3}$ concentrations in groundwater are mostly related with the use of organic or synthetic fertilizers; recent studies reported that this kind of anthropogenic impact affects also major ions concentrations such as $\mathrm{Cl}, \mathrm{SO}_{4}, \mathrm{Ca}$ and $\mathrm{Mg}$. Thus, the profile of this fifth factor was associated to the anthropogenic impact related to the agricultural land use, not just in terms of $\mathrm{NO}_{3}$ but also considering the contribution of different elements. 